\title{
Quality characteristics of Ilmenit minerals in the south central of Vietnam by SEM and QEMSCAN analysis
}

\author{
Hiep Huu Nguyen 1,2,3, , Andrew Carter ${ }^{3}$, Din Bui Dao ${ }^{4}$, Luc The Trinh ${ }^{3}$, Chi Kim \\ Thi Ngo ${ }^{2}$, Dao Anh Vu ${ }^{2}$, Binh Van Phan ${ }^{2}$, Huy Quang Nguyen ${ }^{5}$ \\ ${ }^{1}$ Center for Excellence in Analysis and Experiment, Hanoi University of Mining and Geology, Vietnam \\ ${ }^{2}$ Faculty of Geosciences and Geoengineering, Hanoi University of Mining and Geology, VietNam \\ ${ }^{3}$ Department of Earth and Planetary Sciences, Birkbeck University of London, U.K. \\ ${ }^{4}$ Office of Ministry of Natural Resources and Environment \\ ${ }^{5}$ Northwest Geological Division, General Department of Geology and Minerals of Vietnam
}

\begin{tabular}{l} 
ARTICLE INFO \\
\hline Article history: \\
Received 19th Nov 2019 \\
Revised 03 $3^{\text {rd }}$ Jan. 202 \\
Accepted 28 $8^{\text {th }}$ Feb. 202 \\
Keywords: \\
Placer, \\
Ilmenite, \\
SEM and QEMSCAN, \\
EDS stone.
\end{tabular}

ABSTRACT

Placer deposit along the South Central Coast of Viet Nam is formed by the enrichment of heavy minerals through a combination of transportation, weathering, erosion and deposition processes. Ilmenite placer forms continuously along the South Central Coast from local origin when the shoreline is far from the modern shoreline formed during the marine transgression process from the late Plestocene to Holocene. The morphological and localization characteristics of Ilmenite have been clarified on the distribution trend with SEM method combined with QEMSCAN. Meticulous research on Ilmenite's grain structure and chemical composition in the study area has shown a tendency to significantly enrich the quality of Ti placer according to the upward trend in the north-south direction. In the south, the Ilmenite placer has smaller particle size but better selective roundness and better quality than in the northern part of the study area. The enrichment of $\mathrm{TiO}_{2}$ content with increasing trend from North to South was observed due to the strong weathering process associated with ancient coastline which is very far away from current shoreline so heavy minerals are accumulates locally and light minerals are carried away. The southern region of the South Central Coast region is home to the highest gap between the ancient shoreline and the current coastline. This study has shown the trend of the quality distribution of Ilmenite as well as of other heavy minerals as the basis for future mineral exploration planning.

Copyright (C) 2020 Hanoi University of Mining and Geology. All rights reserved.

\footnotetext{
${ }^{*}$ Corresponding author

E-mail: nguyenhuuhiep@humg.edu.vn

DOI: 10.46326/JMES.2020.61(1).08
} 


\title{
Tạp chí Khoa học Kỹ thuật Mỏ - Địa chất
}

\section{Đặc điểm chất lượng sa khoáng Ilmenit vùng ven biển Nam Trung Bộ trên cơ sở phân tích SEM và QEMSCAN}

\author{
Nguyễn Hữu Hiệp 1,2,3, ${ }^{*}$ Andrew Carter ${ }^{3}$, Đào Bùi Din ${ }^{4}$, Trịnh Thế Lực ${ }^{3}$, Ngô Thị \\ Kim Chi ${ }^{2}$, Vũ Anh Đạo ${ }^{2}$, Phan Văn Bình ${ }^{2}$, Nguyễn Quang Huy ${ }^{5}$ \\ ${ }^{1}$ Trung tâm Phân tích, Thí nghiệm Công nghệ cao, Trường Đại học Mỏ - Địa chất, Việt Nam \\ ${ }^{2}$ Khoa Khoa học và Kỹ thuật Địa chất, Trường Đại học Mỏ - Địa chất, Việt Nam \\ ${ }^{3}$ Department of Earth and Planetary Sciences, Birkbeck University of London, U.K. \\ ${ }^{4}$ Văn Phòng Bộ Tài Nguyên và Môi trường, Việt Nam \\ ${ }^{5}$ Liên đoàn Địa chất Tây Bắc, Tổng cục Địa chất và Khoáng sản Việt Nam, Việt Nam
}

\begin{tabular}{|c|c|}
\hline THÔNG TIN BÀI BÁO & TÓM TẮT \\
\hline $\begin{array}{l}\text { Quá trình: } \\
\text { Nhận bài 19/11/2019 } \\
\text { Sưa xong 03/01/2020 } \\
\text { Chấp nhận đăng 28/02/2020 }\end{array}$ & 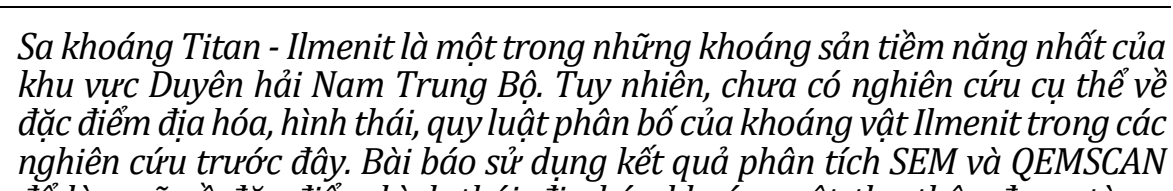 \\
\hline $\begin{array}{l}\text { Tùr khóa: } \\
\text { Sa khoáng, } \\
\text { Ilmenite, } \\
\text { SEM và QEMSCAN, } \\
\text { EDS đá. }\end{array}$ & 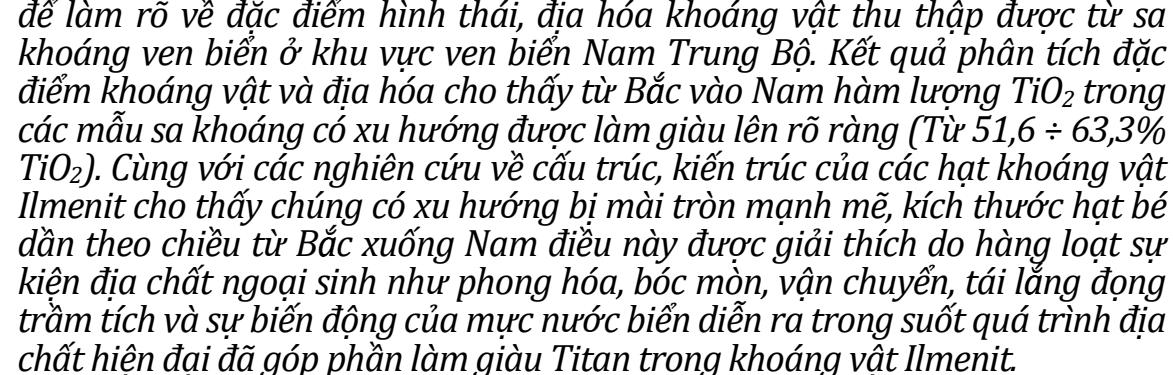 \\
\hline
\end{tabular}

(C) 2020 Trường Đại học Mỏ - Địa chất. Tất cả các quyền được bảo đảm.

\section{Mở đầu}

Sa khoáng Titan ven biển Nam Trung bộ tập trung dọc các đụi cát ven biển, và bãi cát dọc đường bờ. Quá trình lắng đọng tích tụ sa khoáng do sự dịch chuyển, dao động mực nước biển trong suốt giai đoạn Pleitocene đến Holocene. Vùng ven

\section{${ }^{*}$ Tác giả liên hê}

E- mail: nguyenhuuhiep@humg.edu.vn

DOI: 10.46326/JMES.2020.61(1).08 biển Ninh Thuận đến Vũng Tàu là nơi tập trung nhiều mỏ sa khoáng Titan có giá trị cao, hàm lượng Ilmenit trong cát dao động từ $10 \div 100$ $\mathrm{kg} / \mathrm{m}^{3}$, diện phân bố khá đa dạng với chiều dày $1 \div 4 \mathrm{~m}$, chiều rộng từ 1 đến $3 \mathrm{~km}$ và kéo dài lên đến $10 \mathrm{~km}$ (Hình 1). Trong nghiên cứu này nhóm nghiên cứu tập trung tìm hiểu sự thay đổi hàm lượng $\mathrm{TiO}_{2}$ trong khoáng vật Ilmenit cũng như hình thái của lmenit ở các điểm mỏ khác nhau để xác định chất lượng và luận giải quá trình vận chuyển, lắng đọng tích tụ sa khoáng. 


\section{2. Đặc điểm Địa chất - Địa mạo khu vực ven biển Nam Trung Bộ}

Trong khu vực nghiên cứu phổ biến có 3 phức hệ magma tuổi Kreta bao gồm: Định Quán, Đèo Cả và Ankroet. Trong đó, phức hệ Định Quán và Đèo Cả phân bố chủ yếu dọc ven biển. Thành phần thạch học của phức hệ Định Quán bao gồm hornblen- biotit diorit, granodiorit và ít granit. Phức hệ Đèo Cả bao gồm granodiorit, granite hornblen- biotit (pha 1), granit biotit- hornblen, granosyenite và biotit syenite (pha 2 ), và granite porphyry, granular aplite và pegmatite (pha dike mạch). Tuổi Zircon U-Pb của các phức hệ này được ghi nhận từ $88( \pm 1,5) \div 109( \pm 7,0)$ triệu năm (Thủy và nnk., 2004) đến $115,4( \pm 1,2) \div 118,2( \pm 1,4)$ triệu năm (Shellnutt và nnk., 2013). Phức hệ Ankroet bao gồm các đá granite biotit hạt trung bình đến thô, có diện lộ nhỏ hơn phức hệ Định Quán và Đèo Cả và chủ yếu nằm sâu trong đất liền. Tuổi zircon $\mathrm{U}$-Pb trong khoảng 93,4( \pm 2.0$) \div 96,1( \pm 1.1)$ triệu năm (Thủy và nnk., 2004) và $86,8( \pm 1.6) \mathrm{Ma}$
(Shellnutt và nnk., 2013).

Trầm tích cơ học Kainozoi nguồn gốc sông biển trong vùng nghiên cứu bao gồm hệ tầng Di Linh tuổi Oligo - Miocene, hệ tầng Sông Lũy tuổi Piocene sớm - Pleistocene, hệ tầng Ba Miêu tuổi Pliocene muộn - Pleistocene. Kết quả phân tích tuổi các hạt Zircon U-Pb trong các hệ tầng này đều ghi nhận sự phổ biến của phổ tuổi Kreta, Permian - Triassic và Ordovic - Silua. Ngay cả trong hệ tầng trẻ nhất cũng ghi nhận sự có mặt đáng kể của các hạt Zircon tuổi tiền Cambri (Hennig và nnk., 2018). Trong vùng nghiên cứu Bazan Kainoizoi cũng phân bố rộng khắp với chiều dày lên đến vài trăm mét (Hoàng và Flower, 1998). Magma bazan kiềm bắt đầu xuất hiện từ Miocene giữa có đặc điểm địa hóa giống với nguồn vỏ đại dương biến chất tái sinh từ loạt Manti Hải Nam (An và nnk., 2017). Quá trình phun trào và dòng dung nham thường xuất hiện trong những đới đứt gãy địa phương tái hoạt động liên quan đến việc mở ra Biển Đông.

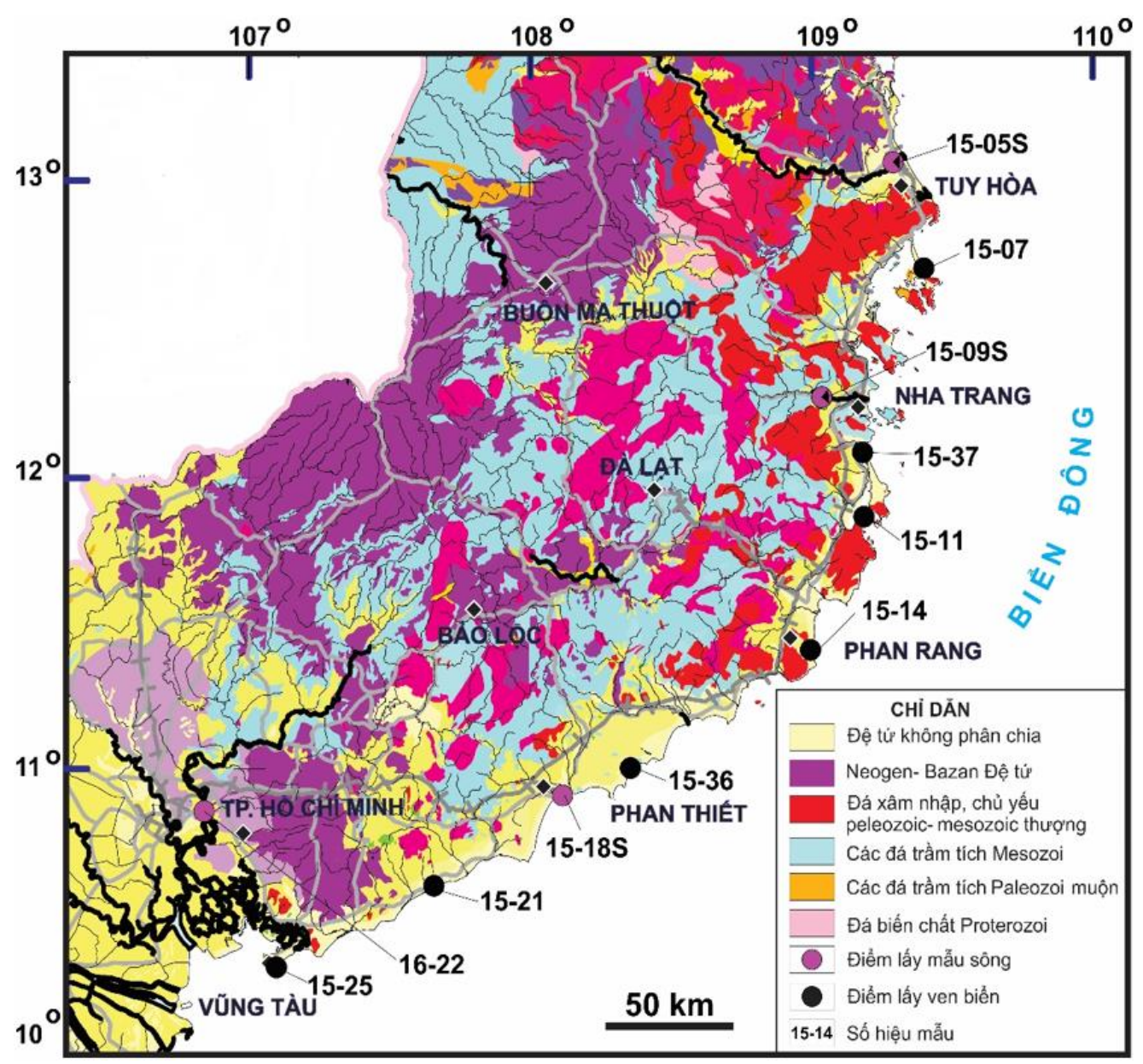

Hình 1. Sơ đồ địa chất vùng nghiên cứu. 


\section{Phương pháp nghiên cứu}

Để đánh giá hình thái cấu trúc các mẫu trầm tích vụn cửa sông và ven biển vùng nghiên cứu, nhóm tác giả đã phân tích mẫu với ảnh SEM với độ phân giải cao (Hình 4). Ảnh SEM với độ phân giải cao của bề mặt mẫu vật bằng cách sử dụng một chùm điện tử (chùm các electron) được phát ra từ súng phóng điện tử (có thể là phát xạ nhiệt, hay phát xạ trường,...), sau đó được tăng tốc. Điện tử được phát ra, tăng tốc và hội tụ thành một chùm điện tử hẹp (cỡ vài trăm Angstrong đến vài nanomet) nhờ hệ thống thấu kính từ, sau đó quét trên bề mặt mẫu nhờ các cuộn quét tĩnh điện. Độ phân giải (độ phóng đại) của SEM được xác định từ kích thước chùm điện tử hội tụ. Ngoài ra, độ phân giải của SEM còn phụ thuộc vào tương tác giữa vật liệu tại bề mặt mẫu vật và điện tử.

Việc xác định các loại khoáng vật khác nhau trong mẫu cát và mối tương quan của chúng được thực hiện bằng phương pháp phân tích thành phần nguyên tố bán định lượng SEM - EDS (phổ năng lượng tán xạ tia X) kết hợp với QEMSCAN.
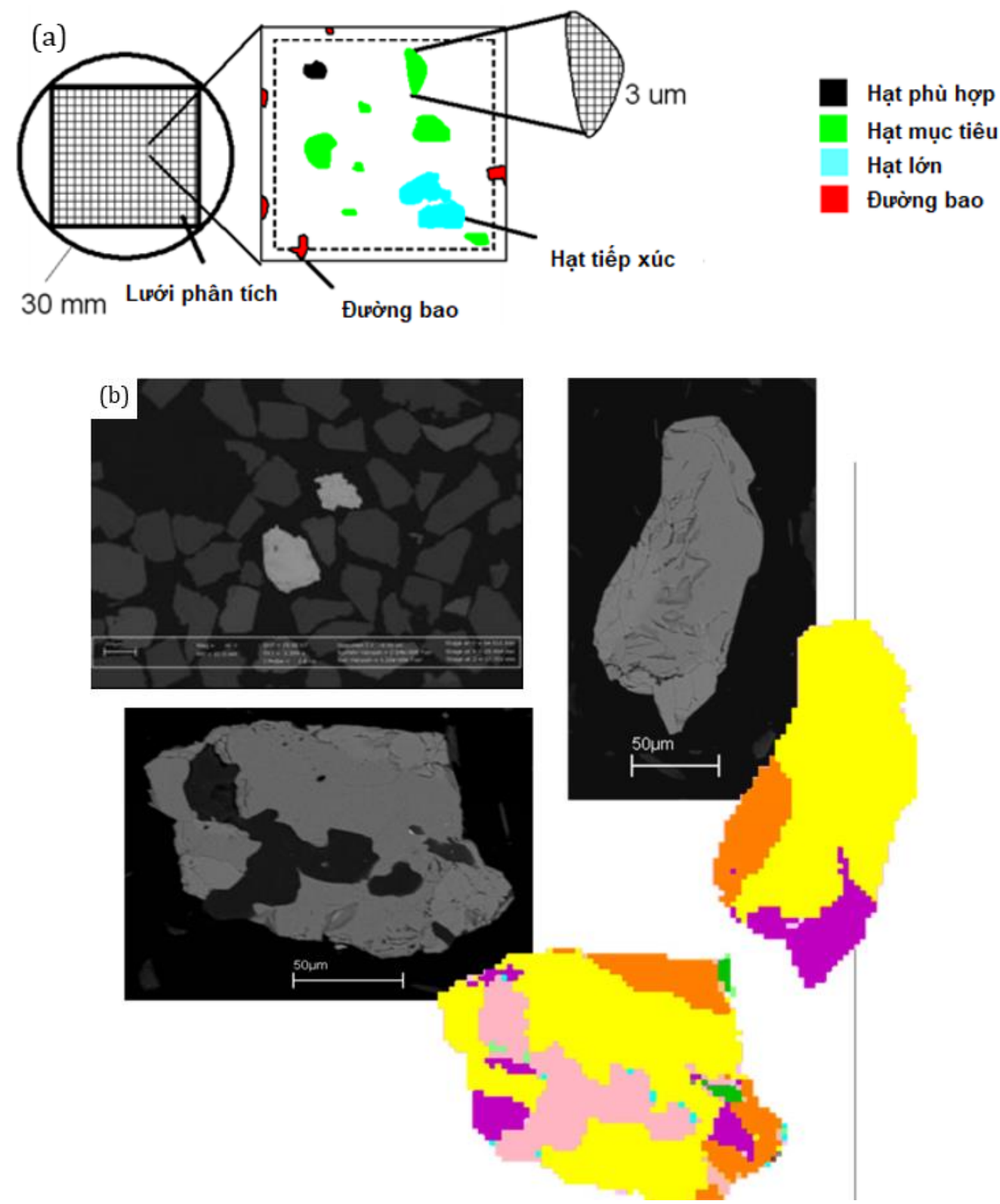

Hình 2: Quy trình phân tích QEMSCAN (a) Lựa chọn mạng lưới phân tích và các yếu tố trong lưới;

(b) Änh SEM và QEMSCAN). 
- QEMSCAN là giải pháp xác định khoáng sản và thạch học tự động tích hợp cung cấp phân tích định lượng khoáng sản, đá và vật liệu nhân tạo. QEMSCAN là tên viết tắt của Đánh giá định lượng khoáng sản bằng kính hiển vi điện tử và được đăng ký thuộc sở hữu của Công ty FEI từ năm 2009. QEMSCAN cho phép lập bản đồ quy mô micron và nhận dạng các loại khoáng vật có mặt trong mẫu (Pirrie and Rollinson, 2011) (Hình 2). Mẫu cát được gia công ghim trên một tấm kính sau đó được mài bóng và được quét với độ phân giải $10 \mu$ m (mỗi mẫu khoảng $1000 \div 12000$ hạt). Mẫu sẽ được chia mạng lưới phân tích. Cấu trúc của các hạt khoáng vật được xác định bằng ảnh BSE (Back Scatter Image). Thành phần hóa được quét toàn bộ mạng lưới chia sẵn (EDS - Mapping). Quang phổ EDS thu được sẽ được tự động luận giải các khoáng vật xuất hiện trên bề mặt mẫu quét (Hình 2). Đồng thời phần mềm sẽ tự động thống kê xác định hàm lượng của từng loại khoáng vật.

- Phương pháp QEMSCAN ra đời tạo ra một giải pháp tối ưu để xác định thành phần khoáng vật đối với nghiên cứu thạch học. Về thành phần khoáng vật gần như QEMSCAN có thể nhận dạng được hầu hết các khoáng vật đã được biết đến. QEMSCAN là giải pháp tin cậy cao trong xác định thành phần khoáng vật nhưng nó cũng có những hạn chế riêng của phương pháp so với phương pháp thạch học dưới kính hiển vi phân cực. QEMSCAN không nhận biết và xác định được các tính chất của mạng tinh thể trong khoáng vật như cát khai. Các đặc điểm về độ trưởng thành và biến chất của khoáng vật cũng không được ghi nhận trên QEMSCAN. Một ví dụ đó là thạch anh đơn tinh và thạch anh đa tinh thể. Nếu sử dụng phương pháp QEMSCAN chỉ nhận biết được tổng hàm lượng thạch anh trong mẫu.

- Phương pháp SEM - EDS được sử dụng để xác định hàm lượng $\mathrm{TiO}_{2}$ trong khoáng vật Ilmenit. EDS: Phổ tán sắc năng lượng tia X (Energy Dispersive X-ray Spectroscopy - EDXS) hay phổ tán sắc bước sóng tia $\mathrm{X}$ (Wavelength Dispersive Xray Spectroscopy - WDXS),... là kỹ thuật phân tích thành phần hóa học của vật rắn dựa vào việc ghi lại phổ tia $X$ phát ra từ vật rắn do tương tác với các bức xạ (mà chủ yếu là chùm điện tử có năng lượng cao trong các kính hiển vi điện tử). Để đánh giá sự thay đổi hàm lượng $\mathrm{TiO}_{2}$ ở những điểm mỏ khác nhau. Mỗi mẫu thu thập được sẽ lựa chọn ngẫu nhiên khoảng 100 hạt ilemenit để phân tích.

\section{Kết quả nghiên cứu và thảo luận}

Phân tích đặc điểm sa khoáng Ilmenit trong vùng nghiên cứu tác giả thu thập 11 mẫu trầm tích vụ cơ học. Trong đó 4 mẫu lấy ở cửa của các con sông và 7 mẫu lấy ở dọc ven biển nơi tập trung các tích tụ sa khoáng. Mục tiêu nhằm đánh giá sự thay đổi về hình thái, kích thước và hàm lượng Ilmenit. Trong đó 07 mẫu trầm tích vụn ven biển được xác định thành phần khoáng vật với phương pháp Qemscan; 11 mẫu trầm tích vụn phân tích cấu trúc kiến trúc hạt với ảnh SEM; 11 mẫu được gia công và phân tích thành phần hóa của đơn khoáng Ilmenite với phương pháp SEM - EDS.

\section{1. Đặc điểm hình thái khoáng vật Ilmenit}

Về hình thái của vật liệu trầm tích: Cấu trúc hạt khoáng vật được phân tích dưới ảnh kính hiển vi điện tử quét (SEI). Mẫu được gắn lên kính nền sau đó quét toàn bộ diện tích bề mặt xác định ảnh cấu trúc cộng với thống kê về kích thước để xác định hình thái của trầm tích vụn của các mẫu (Hình 4). Các mẫu trầm tích vụn ven biển có độ mài tròn chọn lọc tốt. Kích thước hạt từ $200 \div 400$ micron, hạt tròn cạnh đến rất tròn cạnh. Độ mài tròn và chọn lọc của các mẫu ven biển Nam Trung Bộ tăng dần từ Bắc vào Nam. Ngược lại hạt thô phân bố ở phía bắc vùng nghiên cứu kích thước hạt từ $300 \div 400$ micron. Phía nam vùng nghiên cứu hạt mịn hơn khoảng $200 \div 300$ micron. Mẫu trầm tích lấy tại vị trí cửa sông có độ chọn lọc thấp kích thước hạt giao động từ 200 700 micron, hạt góc cạnh đến rất góc cạnh.

Về thành phần hạt vụn trầm tích: Thành phần khoáng vật được xác định bằng phương pháp QEMSCAN với độ chính xác cao. Mỗi mẫu được gia công thành 2 loại mẫu để phân tích (Hình 3). Mẫu tổng (bulk) với thành phần hạt vụn nguyên thủy của mẫu được gắn trên kính nền. Mẫu sau tuyển (rt): thành phần hạt vụn đã qua các quy trình đãi mẫu; thành phần khoáng vật mục tiêu (khoáng vật nặng) được gắn lên kính nền và phân tích SEM EDS và QEMSCAN để xác định chất lượng của sa khoáng Ilmenit. Những mẫu ven biển có thành phần vụn cơ học chủ yếu (Phân tích QEMSCAN) (Hình 3 ) là Ilmenit chiếm từ $1 \div 3 \%$; thạch anh $40 \div 90 \%$, Felspar từ $10 \div 20 \%$; mảnh đá $5 \div 15 \%$; mảnh vụn sinh vật $<1 \%$. Thành phần của 4 mẫu lấy dọc ven các con sông Ilmenit < 1\%, thạch anh $50 \div 80 \%$, Felspar $15 \div 35 \%$, mảnh đá $10 \div 20 \%$; mảnh vụn sinh vật $<5 \%$. 

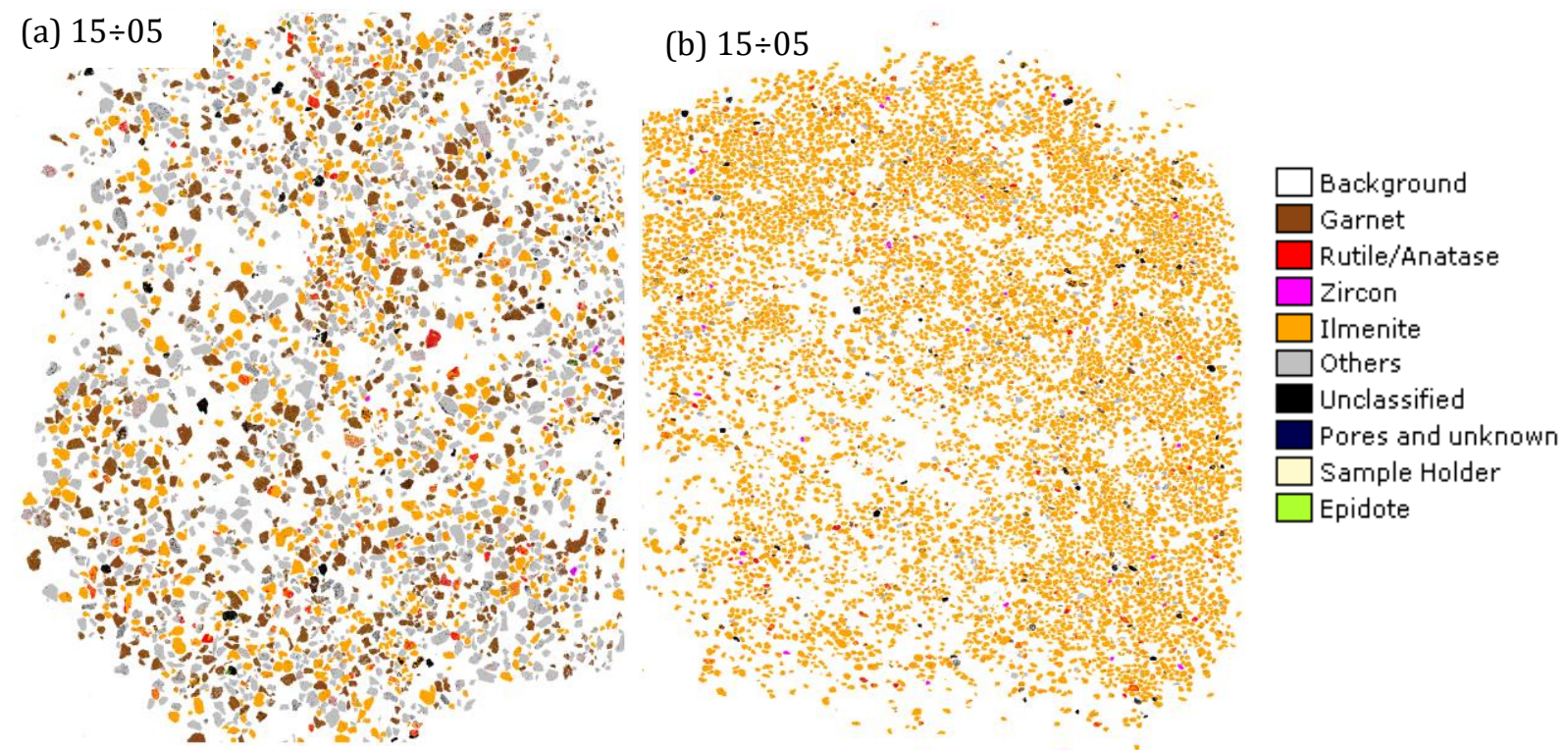

Hình 3. Ảnh QEMSCAN (a) mẫu tổng (bulk); (b) Mẫu sau tuyển (rt).

Bảng 1. Thành phần thạch học xác định bằng phương pháp QEMSCAN.

\begin{tabular}{|c|l|c|c|c|c|c|c|c|}
\hline TT & Thành phần & $15 \div 05$ & $15 \div 07$ & $15 \div 08$ & $15 \div 09$ & $15 \div 14$ & $15 \div 21$ & $15 \div 25$ \\
\hline 1 & Tổng số hạt & 7355 & 3857 & 1586 & 11709 & 10426 & 4553 & 7151 \\
\hline 2 & Quartz & 40,02 & 92,46 & 94,02 & 50,51 & 69,24 & 92,61 & 88,63 \\
\hline 3 & Plagioclase Feldspars & 13,85 & 0,09 & 0,05 & 6,70 & 0,62 & 0,10 & 0,19 \\
\hline 4 & Alkali Feldspars & 20,27 & 2,40 & 2,11 & 15,94 & 13,35 & 0,93 & 0,90 \\
\hline 5 & Biotite & 0,12 & 0,01 & 0,01 & 0,18 & 0,03 & 0,01 & 0,02 \\
\hline 6 & Muscovite & 2,06 & 0,05 & 0,02 & 1,96 & 0,67 & 0,09 & 0,09 \\
\hline 7 & lhlorite & 0,26 & 0,00 & 0,01 & 0,40 & 0,02 & 0,01 & 0,01 \\
\hline 8 & Smectite & 1,24 & 0,07 & 0,03 & 1,42 & 1,13 & 0,10 & 0,13 \\
\hline 9 & Illite & 2,74 & 0,16 & 0,08 & 3,30 & 1,90 & 0,17 & 0,16 \\
\hline 10 & Kaolinite/Dickite & 1,22 & 0,38 & 0,18 & 8,06 & 3,25 & 0,37 & 0,53 \\
\hline 11 & Other Clays & 1,14 & 0,94 & 0,65 & 3,61 & 2,06 & 0,95 & 1,09 \\
\hline 12 & Glauconite & 0,17 & 0,00 & 0,00 & 0,01 & 0,01 & 0,00 & 0,01 \\
\hline 13 & Garnet & 0,84 & 0,02 & 0,00 & 0,24 & 0,02 & 0,01 & 0,07 \\
\hline 14 & Amphibole & 1,89 & 0,01 & 0,01 & 0,65 & 0,06 & 0,10 & 0,05 \\
\hline 15 & Rutile/Anatase & 0,47 & 0,12 & 0,01 & 0,13 & 0,13 & 0,24 & 0,21 \\
\hline 16 & Tourmaline & 0,45 & 0,08 & 0,18 & 1,11 & 0,18 & 0,22 & 0,21 \\
\hline 17 & Zircon & 0,00 & 0,03 & 0,01 & 0,01 & 0,04 & 0,08 & 0,02 \\
\hline 18 & Calcite/Aragonite & 1,77 & 0,00 & 0,00 & 0,00 & 0,00 & 0,00 & 0,02 \\
\hline 19 & Siderite-Magnesite & 0,03 & 0,00 & 0,00 & 0,05 & 0,01 & 0,00 & 0,00 \\
\hline 20 & Pyrite/Marcasite & 0,01 & 0,00 & 0,00 & 0,00 & 0,00 & 0,00 & 0,00 \\
\hline 21 & Ilmenit & 1,40 & 0,12 & 0,09 & 0,09 & 0,61 & 0,82 & 0,16 \\
\hline 22 & Sillimanite/Kyanite/Andalusite & 0,04 & 0,11 & 0,00 & 0,02 & 0,02 & 0,08 & 0,06 \\
\hline 23 & Fe Oxide & 0,18 & 0,00 & 0,00 & 0,02 & 0,08 & 0,01 & 0,00 \\
\hline 24 & Titanite & 0,29 & 0,00 & 0,00 & 0,00 & 0,00 & 0,00 & 0,00 \\
\hline 25 & Staurolite & 0,04 & 0,00 & 0,00 & 0,04 & 0,00 & 0,00 & 0,01 \\
\hline 26 & Others & 0,20 & 0,00 & 0,00 & 0,21 & 0,02 & 0,01 & 0,01 \\
\hline 27 & Pores and unknown & 8,92 & 2,92 & 2,54 & 5,25 & 6,54 & 3,05 & 7,39 \\
\hline
\end{tabular}




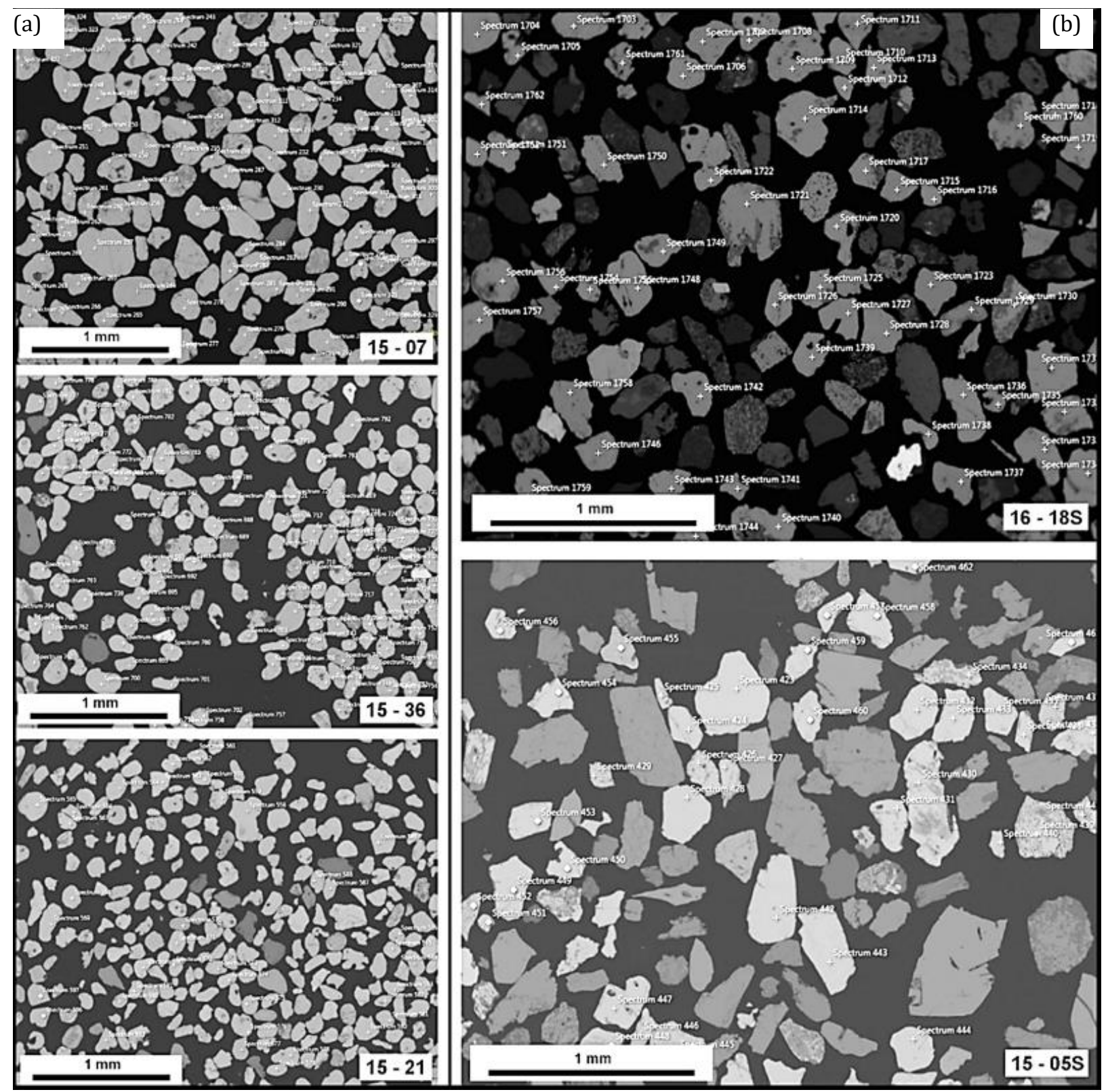

Hình 4. Hình ảnh các mẫu Ilment quét trên máy SEM, (a) mẫu sa khoáng Ilment ở ven biển nơ tập chung cao Ilmenit; (b) Mẫu lấy ở sông.

\section{2. Đắc điểm thành phần hóa của khoáng vật Ilmenit}

Phương pháp SEM-EDS được sử dụng để đánh giá chất lượng của khoáng vật Ilmenit. Số lượng hạt khoáng vật được phân tích từ $73 \div 110$ hạt trên một mẫu. Từ kết quả phân tích thành phần hóa của các mẫu, cho thấy xu hướng tăng đáng kể của thành phần $\mathrm{TiO}_{2}$ của trong Ilmenit theo chiều từ Bắc - Nam. Các hạt Ilmenit trên Hình 4 cho thấy thành phần của oxit Titan được làm giàu lên đáng kể từ $51,46 \div 62,56 \%$ theo xu hướng từ Bắc vào
Nam. Hay nói cách khác các mẫu lấy tại ven biển Nam Trung Bộ có chất lượng tốt dần theo hướng Bắc - Nam.

Đồng thời phương pháp QEMSCAN cũng được sử dụng để xác định đặc điểm thành phần của khoáng vật Ilmenit (Hình 6). Các mẫu Ilmenit tại cửa sông vẫn chứa nhiều bao thể của zircon và các thành phần khác (độ rỗng, garnet, rutile). Mẫu Ilmenit ven biển có độ hạt mịn hơn, chứa ít bao thể hơn, cộng với Ilmenit phía nam khu vực lại có độ hạt nhỏ hơn và độ mài tròn chọn lọc tốt hơn. 
Bảng 2. Bảng rút gọn phân tích thành phần $\mathrm{TiO}_{2}$ trong khoáng vật Ilmenit bằng phưong pháp SEM -EDS.

\begin{tabular}{|l|l|c|c|c|c|c|c|c|c|c|c|c|}
\hline \multirow{2}{*}{ TT } & \multicolumn{1}{|c|}{ TT } & $\begin{array}{c}15 \div 01 \\
(\%)\end{array}$ & $\begin{array}{c}15 \div 05 \\
(\%)\end{array}$ & $\begin{array}{c}15 \div 07 \\
(\%)\end{array}$ & $\begin{array}{c}15 \div 09 \\
(\%)\end{array}$ & $\begin{array}{c}15 \div 37 \\
(\%)\end{array}$ & $\begin{array}{c}15 \div 11 \\
(\%)\end{array}$ & $\begin{array}{c}15 \div 14 \\
(\%)\end{array}$ & $\begin{array}{c}15 \div 36 \\
(\%)\end{array}$ & $\begin{array}{c}15 \div 18 \\
(\%)\end{array}$ & $\begin{array}{c}15 \div 21 \\
(\%)\end{array}$ & $\begin{array}{c}15 \div 25 \\
(\%)\end{array}$ \\
\hline 1 & Tổng số hạt phân tích & 100 & 103 & 96 & 73 & 110 & 114 & 107 & 106 & 102 & 105 & 110 \\
\hline 2 & Nhỏ nhất & 40,49 & 44,51 & 31,84 & 41,58 & 56,42 & 40,49 & 45,4 & 47,55 & 44,05 & 48,94 & 52,12 \\
\hline 3 & Lớn nhất & 73,44 & 59,87 & 58,15 & 68,08 & 72,85 & 86,18 & 65,4 & 86,43 & 78,86 & 97,82 & 98,11 \\
\hline 4 & Trung bình & 51,46 & 51,92 & 52,445 & 54,32 & 63,3 & 60,07 & 54,61 & 54,05 & 56,23 & 57,25 & 62,56 \\
\hline
\end{tabular}

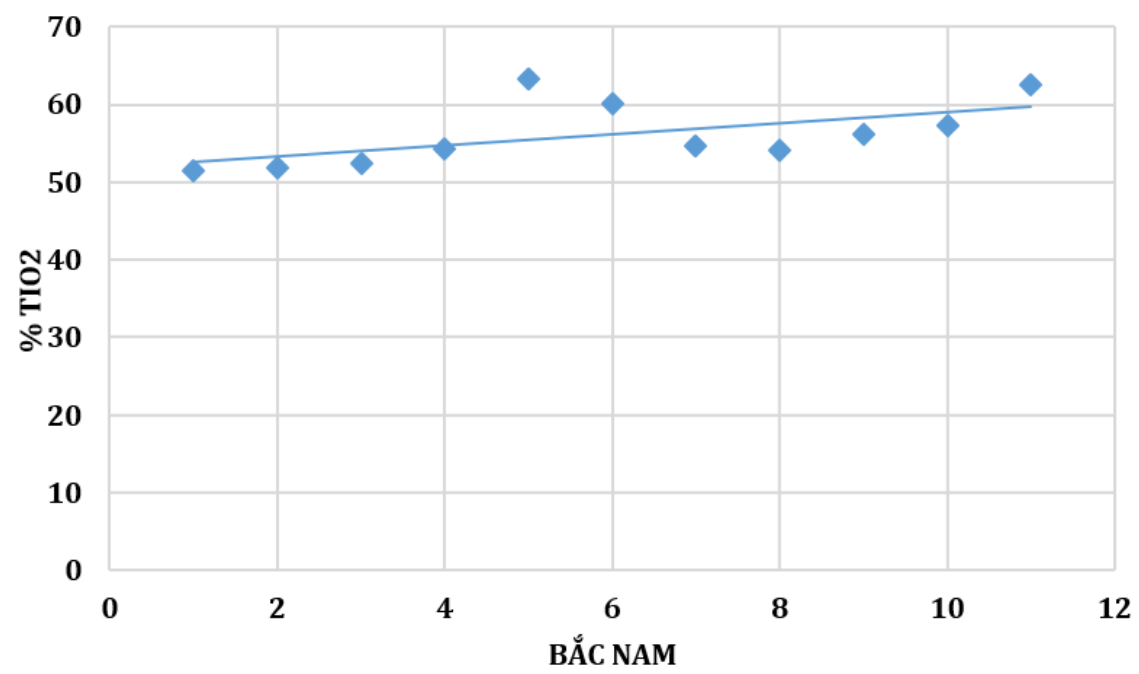

Hình 5. Biểu đồ hàm lượng oxit Ti trong các hạt Ilmenit ở các mẫu thu thập ven biển Nam Trung Bộ.

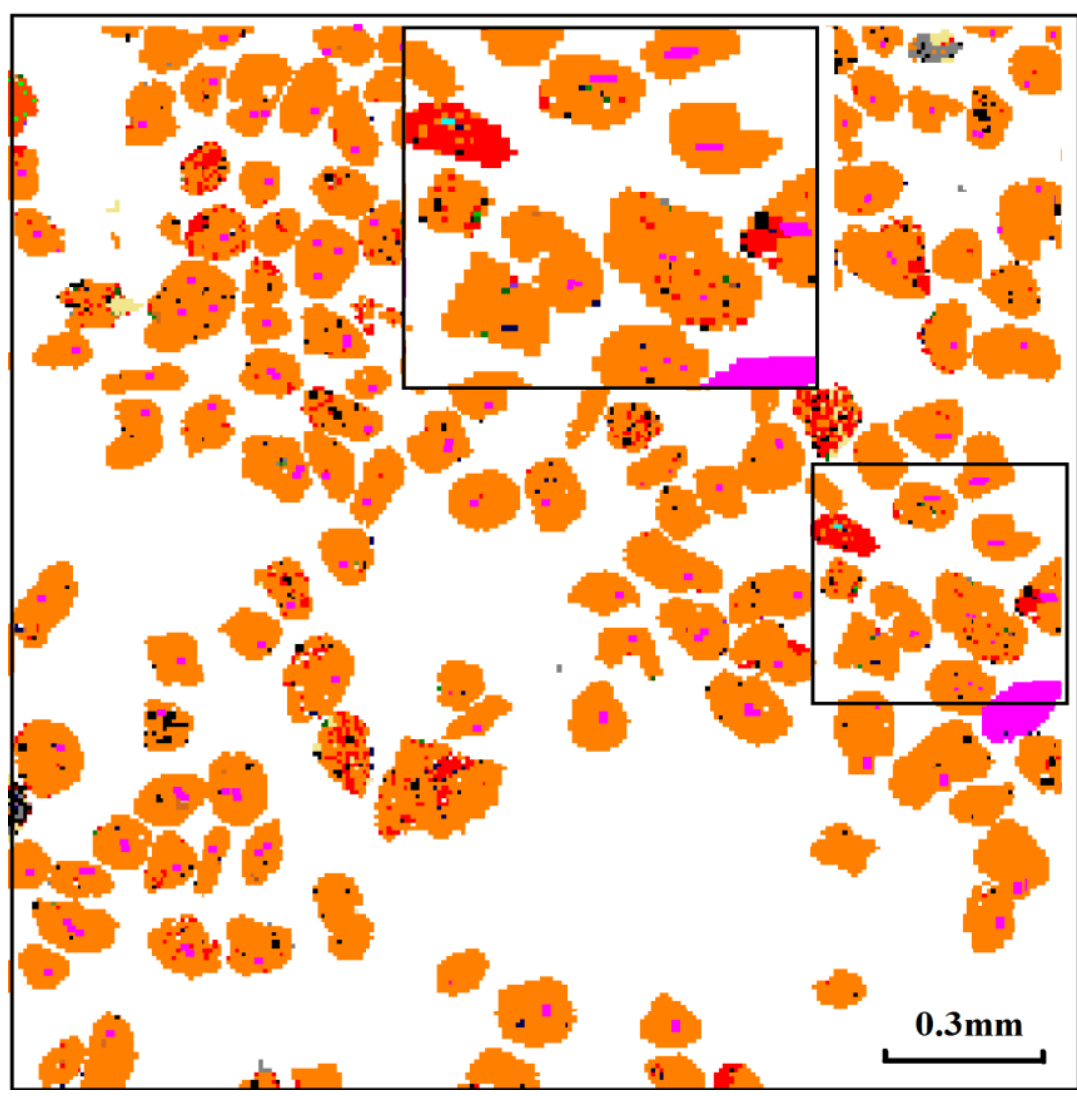

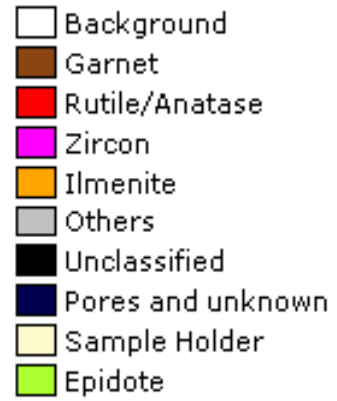

Hình 6. Hình ảnh thu được khi quét các hạt Ilmenit bằng máy Qemscan. 


\section{Thảo luận}

\subsection{Các cơ chế vận chuyển vật liệu làm tăng độ chọn lọc Ilmenit}

Các tích tụ Ilmenit có nguồn gốc địa phương (Trần Văn Trị và nnk., 2009; Nguyễn Hữu Hiệp và nnk., 2018) được thành tạo từ quá trình phong hóa hình thành các vật liệu trầm tích và được vận chuyển qua các dòng chảy của những con sông trong khu vực Nam Trung Bộ. Có thể thấy rõ ràng chất lượng của sa khoáng Ilmenit được làm giàu lên rõ rệt qua kết quả phân tích SEM - EDS các mẫu dọc ven biển Nam Trung Bộ. Trên Hình 4, các mẫu vụn trầm tích lấy tại phía bắc Nam Trung Bộ $(15 \div 05 ; 15 \div 09)$ có kiến trúc hạt từ góc cạnh đến bán tròn cạnh. Các mẫu trung tâm vùng nghiên cứu các hạt Ilmenit có hình thái bán tròn cạnh đến tròn cạnh $(15 \div 11)$, Ilmenit nằm tại phía nam vùng nghiên cứu hạt tròn cạnh cộng với có độ chọn lọc cao $(15 \div 14 ; 15 \div 21 ; 15 \div 25)$. Có thể nhận thấy rõ ràng về xu thế tích tụ vật liệu trầm tích: Vật liệu trầm tích (bao gồm Ilmenit và các khoáng vật nặng khác) được thành tạo từ phong hóa các thành tạo địa chất địa phương, được vận chuyển theo gió và các dòng chảy ra ven biển Nam Trung Bộ và tích tụ theo hướng từ Bắc vào Nam. Do đó vùng ven biển phía Nam của khu vực Nam Trung bộ có tiềm năng rất lớn về Ilmenit và các khoáng vật nặng khác.

Ngoài ra, hệ thống gió mùa cũng đóng vai trò quan trọng, trong khu vực Đông Á. Hệ thống gió mùa thổi theo hướng Đông Bắc và mùa đông và theo hướng Tây Nam vào mùa hè, gió mùa đông Bắc có tác động lớn ở phía Bắc còn gió Tây Nam ảnh hưởng đến khu vực miền Trung và miền Nam (Pham, 2003). Sự thay đổi liên tục của hệ thống gió mùa cũng sẽ tác động đến dòng chảy dọc bờ cùng với đó là tác động của yếu tố địa mạo ven bờ gây khó khăn cho việc dự đoán xu hướng dịch chuyển dài hạn của trầm tích ven bờ.

\section{5,2, Xu hướng phân bố theo chất lượng của khoáng sản Ilmenit}

Phương pháp SEM-EDS được sử dụng trên các mẫu ven biển Nam Trung Bộ để đánh giá chất lượng khoáng sản Ilmenit thông qua việc xác định thành phần Titan có trong khoáng vật này. Từ biểu đồ hàm lượng oxit Ti (Hình 5) trong các hạt Ilmenit có thể thấy rõ chất lượng Ilmenit tăng đáng kể theo chiều từ Bắc vào Nam. Nguyên nhân của sự tăng đáng kể về chất lượng của sa khoáng Ilmenit do các mẫu trầm tích tập trung tích tụ các khoáng vật nặng nằm dọc đường bờ biển và đường bờ cổ cho thấy sự thay đổi mực nước biển trong quá khứ (Hình 7). Các kết quả phân tích phát sáng quang học kích thích (OSL) chỉ ra các đụn cát tuổi già nhất bắt gặp ở Suối Tiên và Hòn Gốm (Quang Minh và nnk., 2010) có chứa các tập cát giàu Ilmenit và zircon. Như vậy, giai đoạn lắng đọng trầm tích $8,3( \pm 0,6) \div 6,2( \pm 0,3)$ ka $\mathrm{BP}$, tương đồng với giai đoạn biển tiến cực đại địa phương. Trong giai đoạn này lượng trầm tích được tích tụ rất lớn. Cát đỏ nguồn gốc trầm tích biển nông ở Suối Tiên có tuổi già hơn 101( \pm 16$) \mathrm{ka}$, trong khi tập cát trắng ở đáy có tuổi OSL 276( \pm 17$)$ ka tương ứng với giai đoạn đầu của mực nước biển tăng (Stattegger và nnk., 2013).

Quá trình biển tiến làm tăng độ tập trung và chất lượng của khoáng sản Titan dọc ven biển Nam Trung Bộ. Nguồn vật liệu Ilmenit có nguồn gốc địa phương được cung cấp liên tục từ các con sông chính ra biển Đông. Trong giai đoạn Plestocen là giai đoạn biển thoái cực đại tạo ra một thềm lục địa mở rộng cực đại. Giai đoạn này các quá trình phong hóa diễn ra mạnh mẽ. Đây là thời gian mất trầm tích; trầm tích từ những con sông được vận chuyển ra rất xa so với đường bờ biển hiện nay. Mặt tích cực của giai đoạn này là các khoáng vật nhẹ sẽ đi xa hơn và lắng đọng lại các khoáng vật nặng tại ven biển. Quá trình tích tụ của sa khoáng ven biển tiếp tục từ suốt quá trình biển tiến từ cuối Plestocen đến Holocen (Hình 8). Từ Holocen đến nay mực nước biển vẫn tiếp tục tăng, thời gian này lượng trầm tích được tích tụ lớn là lớp phủ lên trên các tích tụ sa khoáng.

\section{Kết luận}

Sa khoáng dọc bờ biển Nam Trung Bộ được hình thành do quá trình làm giàu các khoáng vật nặng thông qua sự kết hợp giữa các quá trình vận chuyển, phong hóa, xói lở, lắng đọng. Sa khoáng Ilmenit hình thành liên tục ven biển Nam Trung Bộ từ nguồn gốc địa phương khi đường bờ nằm cách xa đường bờ hiện đại hình thành suốt quá trình biển tiến từ cuối Plestocen đến Holocen. Đặc điểm hình thái và địa hóa của Ilmenit đã được làm rõ về xu hướng phân bố với phương pháp SEM kết hợp QEMSCAN. Với các nghiên cứu tỉ mỉ về cấu trúc hạt và thành phần hóa của Ilmenit trong khu vực nghiên cứu đã chỉ ra xu hướng làm giàu lên 

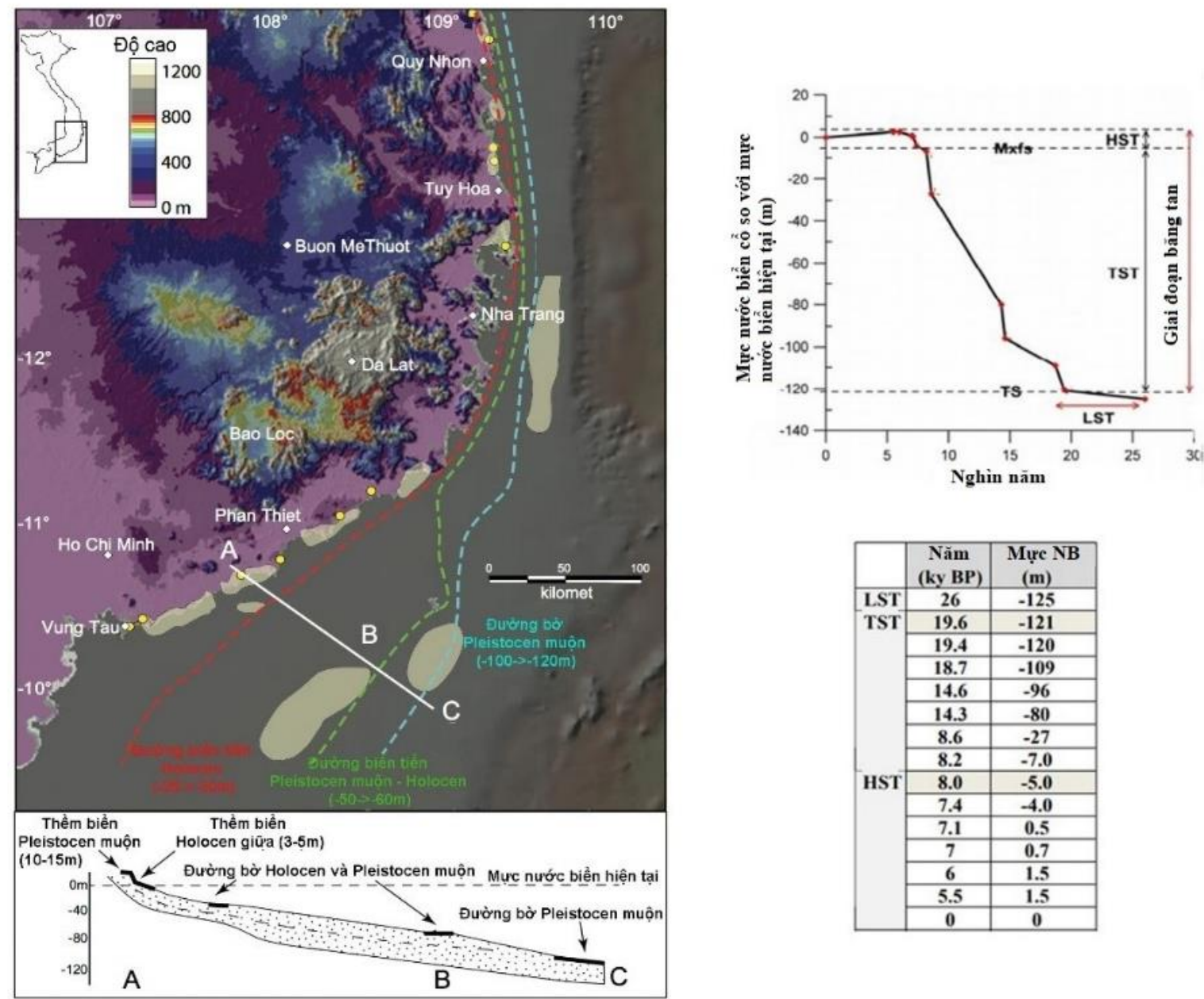

Hình 7. So đồ phân bố tích tụ sa khoáng và đường bờ cổ trong các giai đoạn Holocen và Plestocen. Vùng màu vàng: noi tập chung sa khoáng titan cao, Châm vàng: các điểm mỏ sa khoáng titan.

lên đáng kể về chất lượng của sa khoáng Ti theo xu hướng tốt lên theo chiều Bắc - Nam. Ở phía nam vùng nghiên cứu sa khoáng Ilmenit có kích thước hạt nhỏ hơn nhưng độ mài tròn chọn lọc và chất lượng tốt hơn so với phía bắc vùng nghiên cứu. Sự làm giàu hàm lượng $\mathrm{TiO}_{2}$ theo xu hướng tăng dần từ Bắc vào Nam được quan sát thấy là do quá trình phong hóa diễn ra mạnh kết hợp với đường bờ biển cổ cách rất xa so với đường bờ hiện tại vì thế khoáng vật nặng được tích tụ tại chỗ còn khoáng vật nhẹ được mang ra xa. Vùng phía Nam của khu vực Nam Trung Bộ là nơi có độ chênh lệch cao nhất về khoảng cách đường bờ cổ với đường bờ biển hiện tại. Nghiên cứu này đã chỉ ra xu hướng phân bố về chất lượng của Ilmenit cũng như của các sa khoáng nặng khác là cơ sở cho các công tác quy hoạch tìm kiếm thăm dò khoáng sản sau này.

\section{Lòi cảm ơn.}

Tập thể tác giả xin trân thành cảm ơn Trung tâm Phân tích, Thí nghiệm Công nghệ cao, Trường Đại học Mỏ - Địa chất; Trung tâm London Geochronology Birkbeck University of London, U.K đã hỗ trợ công tác gia công phân tích mẫu. Công trình được hoàn thành từ nguồn kinh phí của đề tài cấp bộ mã số B2018 - MDA - 20DT.

\section{Tài liệu tham khảo}

An, A. R., Choi, S. H., Yu, Y., Lee, D. C., 2017. Petrogenesis of Late Cenozoic basaltic rocksfrom southern Vietnam. Lithos 272, 192204. 
Dũng, B. V., Stattegger, K., Unverricht, D., Phung, V. P., Nguyen, T. T., 2013. Late PleistoceneHolocene seismic stratigraphy of the Southeast Vietnam Shelf. Global and Planetary Change 110, 156-169.

Hennig, J., Breitfeld, H., Gough, A., Hall, R., Van Long, T., Mai Kim, V., Dinh Quang, S., 2018. U$\mathrm{Pb}$ Zircon Ages and Provenance of Upper Cenozoic Sediments from the Da Lat Zone, SE Vietnam: Implications For an Intra-Miocene Unconformity and Paleo-Drainage of the Proto-Mekong River. J. Sediment. Res. 88, 495515.

Hoang, N., Flower, M. F. J., 1998. Petrogenesis of Cenozoic basalts from Vietnam: implication for origins of a 'diffuse igneous province. Journal of Petrology 39, 369-395.

Hiep Huu Nguyen, Andrew Carter, Long Van Hoang, Son Trung Vu. Provenance, routing and weathering history of heavy minerals from coastal placer deposits of southern Vietnam. Sedimentary Geology 373 (2018) 228238.

Pham, V. N., 2003. Bien Dong Monograph, Vol. II-
Meteorology. Hanoi National University Publisher, Hanoi (565 pp., in Vietnamese).

Pirrie, D., Rollinson, G. K., 2011. Unlocking the applications of automated mineral analysis. Geology Today 27, 235-244.

Quang-Minh, D., Frechen, M., Nghi, T., Harff, J., 2010. Timing of Holocene sand accumulation along the coast of central and SE Vietnam. International Journal of Earth Sciences 99, 1731-1740.

Stattegger, K., Tjallingii, R., Saito, Y., Michelli, M., Nguyen, T. T., Wetzel, A., 2013. Mid to Late Holocene sea-level reconstruction of Southeast Vietnam using beachrock and beach-ridge deposits. Global and Planetary Change 110, 214-222.

Thuy, N.T.B., Muharren, S., Wolfgang, S., Fukun, C., 2004. Granitoids in the Dalat zone, southern Vietnam: age constraints on magmatism and regional geological implications. International Journal of Earth Sciences 93, 329-340.

Trần Văn Trị, Vũ Khúc (chủ biên), 2009. Địa chất và tài nguyên Việt Nam. Nhà xuất bản Khoa học tự nhiên và công nghệ. Hà Nội, 2009. 